\title{
Morphology and Mitochondrial Genome of Fischoederius sp. 1 in Thailand
}

\author{
Pichanee Watthanasiri [i], Amornrat Geadkaew-Krenc [i], Rudi Grams* (i] \\ Graduate Program in Biomedical Sciences, Faculty of Allied Health Sciences, Thammasat University, Pathumthani 12121, Thailand
}

\begin{abstract}
A rumen fluke Fischoederius elongatus is assigned to the type species of genus Fischoederius, family Gastrothylacidae. However, the mitochondrial sequences recently published are thought to be of inconsistent species, suggesting that several morphologically similar but genetically distinct species might be classified as Fischoederius elongatus. Thus, mentions of $F$. elongatus from South, Southeast, and East Asia might unintentionally refer to different species. The present work describes morphology and a full mitochondrial genome sequence of one of these species. The fluke specimens were collected from 2 infected cattle in Thailand. An interesting finding was the presence of a second tRNA-Asp gene next to a partial ND1 gene. It is suggested that these duplicated sequences are the remnants of non-reciprocal recombination events caused by inverted repeats located between ND2 and ND1 mitochondrial genes.
\end{abstract}

Key words: Gastrothylacidae, Fischoederius, morphology, mitochondrial genome

\section{INTRODUCTION}

Amphistomes in the genus Fischoederius have been reported from cattle in Thailand [1] and other countries in Asia. A critical phase in amphistomiasis is intense acute infection when the excysted juvenile flukes give severe damage to the duodenal wall, and this again might especially affect naive calves [2]. Human infection seems to be very rare and only a single case was listed in a review on foodborne intestinal flukes from Southeast Asia [3]. One of the Fischoederius species often mentioned is Fischoederius elongatus which is used as the type-species [4,5]. It was first described as Gastrothylax elongatus in 1883 [6] and renamed to F. elongatus upon introduction of the genus Fischoederius in 1910 [7]. At that time F. cobboldi (Poirier, 1883), F. fischoederi, F. ceylonensis, and F. siamensis were also placed in this genus [7]. In 1923 the latter 3 species were synonymized under F. elongatus (Stiles and Goldberger, 1910) [8] with argument that there was no sufficient morphological difference between them. Nowadays the limited set of zoological characteristics that hampered classification in these flukes might be overcome by molecular sequence analysis. Indeed,

- Received 4 May 2021, revised 4 July 2021, accepted 20 July 2021.

*Corresponding author (rgrams@tu.ac.th)

(c) 2021. Korean Society for Parasitology and Tropical Medicine

This is an Open Access article distributed under the terms of the Creative Commons

Attribution Non-Commercial License (https://creativecommons.org/licenses/by-nc/4.0) which permits unrestricted non-commercial use, distribution, and reproduction in any

medium, provided the original work is properly cited. this seems to happen right now because researchers have started to publish conflicting molecular data in the genus Fischoederius. In phylogenetic research on rumen flukes from India, partial ribosomal RNA ITS2 and mitochondrial COX1 sequences were reported from F. cobboldi and F. elongatus $[9,10]$ without supporting morphological evidence. Shortly thereafter researchers from China published the full mitochondrial genome sequences for F. cobboldi (GenBank: NC_030529) and F. elongatus [11]. The current GenBank entry for F. cobboldi does not cite an associated publication, and the F. elongatus publication did not provide morphological evidence. The COX1 sequences from India and China are conflicting for both species. A recent publication from Thailand reported partial COX1 data purported to originate from $F$. elongatus [12]. Again, there are sequence differences among the data from India and China and also sequence differences among their own samples. Morphological evidence was provided but not directly linked to specific sequences because the authors might have assumed that all these sequence differences were intragenic polymorphisms and that their samples represented only 1 species.

In this study, we present linked molecular and morphological data for a single Fischoederius sp. from Thailand. This species was found to follow the classical description of $F$. elongatus. Its molecular data was consistent with partial COX1 data from India [10], but different from the COX1 data from China [11] and Thailand [12]. This begs the question who is the 'real' F. elongatus and who will reverse the synonymization of $F$. fis- 
choederi, F. ceylonensis, and F. siamensis? Ultimately, these conflicts can only be resolved if molecular signatures can be obtained from the original samples described in 1883 and 1910 $[6,7]$. Until then it is important to avoid species designation to prevent ongoing confusion.

\section{MATERIALS AND METHODS}

\section{Collection of parasites}

Parasites were collected from the rumen of 2 naturally infected cattle sacrificed at a local slaughter house (coordinates: $14.0390^{\circ} \mathrm{N}, 100.6207^{\circ} \mathrm{E}$ ) in Pathum Thani province, Thailand on the 5th of August 2014 and the 15th of February 2016. The flukes were washed several times in 1xPBS, $\mathrm{pH}$ 7.4. The worms were either stored in liquid nitrogen until extraction of DNA or RNA or used for preparation of stained whole mounts and paraffin embedded tissue as described in the following sections.

\section{Imaging of unstained parasites}

Images of parasites in cattle rumen and 6-well culture dishes (Thermo Fisher Scientific, Waltham, Massachusetts, USA) were acquired with an ASUS ZenFone ZD551KL (ASUSTeK Computer Inc., Taiwan). Parasites collected in 2014 were flattened in $1 \times$ PBS, pH 7.4 between 2 microscopic slides and images were taken under a Nikon SMZ445 stereo microscope with a C-LEDS Hybrid LED Stand (Nikon Corporation, Japan) at $0.8 \mathrm{X}$ objective magnification using an iPhone 7 (Apple Inc., California, USA) with an iDu LabCam microscope adapter for iPhone 7/8 with multi-fit wide field 10X ocular (iDu Optics LLC, New York, USA). The COX1 sequence of these specimens was subsequently determined from extracted DNA as described below.

\section{Preparation of stained whole mounts}

PBS-washed mature and immature flukes collected in 2014 and 2016, respectively, were flattened between 2 glass slides and fixed in alcohol-formal acetic acid (AFA) fixative overnight. The fixed flukes were dehydrated in 70\% ethanol for 30 min and immersed in Semichon's carmine at room temperature, overnight. The flukes were dehydrated in $80-95 \%$ serial ethanol, 30 min each step, and counterstained with $0.02 \%$ fast green for 2-3 sec. The stained flukes were dehydrated in absolute ethanol, $30 \mathrm{~min}$ and cleared in xylene, $1 \mathrm{hr}$. They were mounted in Permount (Thermo Fisher Scientific) and exam- ined under a light microscope.

\section{Preparation of stained sections}

PBS-washed immature flukes collected in 2016 were fixed in Bouin's fixative solution (Sigma, St. Louis, Missouri, USA) at room temperature, overnight. The fixed flukes were gradually dehydrated in 50-100\% ethanol with each step repeated 3 times, 20 min each step. Absolute ethanol was replaced with xylene 3 times, $10 \mathrm{~min}$ each. The flukes were incubated in $\mathrm{xy}-$ lene: paraplast mixed at ratios 2:1, 1:1, 1:2 at $60^{\circ} \mathrm{C}, 1 \mathrm{hr}$ each step. The flukes were then incubated in pure paraplast at $60^{\circ} \mathrm{C}$, 3 times, $1 \mathrm{hr}$ each step. The embedded tissue was cut into 8 - $\mu \mathrm{m}$ serial cross-sections and the sections were placed on gelatin coated microscopic glass slides and dewaxed and rehydrated. Basophilic substances were stained with progressive hematoxylin for $7 \mathrm{~min}$. Nuclear coloration was converted from reddish purple to a crisp blue by bluing solution for $1 \mathrm{~min}$. Acidophilic substances were stained with eosin for $15 \mathrm{sec}$. The stained tissue was dehydrated in graded ethanol series from $95 \%$ to $100 \%$ for each $1 \mathrm{~min}$, and preserved in xylene, $10 \mathrm{~min}$. The tissue was mounted in xylene based mounting medium and observed under a light microscope.

\section{RNA extraction, NGS sequencing}

Total RNA of 5 immature Fischoederius sp. 1 (Thailand) collected in 2016 was separately extracted in TRIzol reagent (Ambion $^{\text {TM }}$ Life Technologies, Waltham, Massachusetts, USA). The RNA was dissolved in RNase-free water and purified using a QIAgen RNeasy ${ }^{\circledR}$ Plus Mini Kit (QIAgen, Hilden, Germany) to remove contaminating DNA. RT-PCR with primer pair 15/18 (Table 1) was used to amplify a 1,536 bp COX1 fragment from each RNA sample. The PCR products were sequenced to confirm sequence identity between the samples. RNA quality was analyzed by $1.2 \%(\mathrm{w} / \mathrm{v})$ denaturing agarose gel electrophoresis. The concentration of RNA was measured on a NanoDrop ND-2000 UV-Vis spectrophotometer (Thermo Fisher Scientific). RNA at an amount of $14 \mu \mathrm{g}(461 \mathrm{ng} / \mu \mathrm{l})$ was mixed with GenTegra-RNA matrix in a RNAstable tube (Biomatrica, San Diego, California, USA) and dried in a vacuum desiccator, $4 \mathrm{hr}$. Following drying, the pooled RNA was shipped to Vishuo Biomedical, Singapore for NGS sequencing on an Illumina HiSeq instrument. Remaining total RNA was kept at $-80^{\circ} \mathrm{C}$. The Bridger de novo transcriptome assembler [13] was used to assemble the raw data. Mitochondrial sequences among the transcripts were identified by NCBI BLASTN searches using the 
Table 1. PCR primers used in the analysis of the mitochondrial genome of Fischoederius sp. 1 (Thailand)

\begin{tabular}{|c|c|c|c|c|c|}
\hline No. & Start & End & Length & Orientation & Sequence \\
\hline 1 & 60 & 77 & 18 & Reverse & ССТАAСАAСТTССATAAG \\
\hline 2 & 2,907 & 2,927 & 21 & Forward & TGGCGTIITGAGGTTATCAC \\
\hline 3 & 3,764 & 3,781 & 18 & Reverse & CGCAAAACCTTCACACC \\
\hline 4 & 4,149 & 4,177 & 29 & Forward & GTGCGTGGTTATITGTTCTTGGTTGAG \\
\hline 5 & 4,359 & 4,380 & 22 & Reverse & TTGAAACTAAAGCACAAACCAT \\
\hline 6 & 4,671 & 4,690 & 20 & Forward & GCTTCGTTAGTGGCTATGAG \\
\hline 7 & 4,774 & 4,793 & 20 & Forward & TATGTGGTGATGAGATGGTG \\
\hline 8 & 4,871 & 4,888 & 18 & Forward & GTTGTTGATGGGTAGTTG \\
\hline 9 & 4,958 & 4,976 & 19 & Forward & GGTTAAGTITGTAATAGGA \\
\hline 10 & 5,708 & 5,732 & 25 & Forward & TGCTCTGCAAGTACGAGGTGAGTGT \\
\hline 11 & 5,708 & 5,732 & 25 & Reverse & ACACTCACCTCGTACTTGCAGAGCA \\
\hline 12 & 6,258 & 6,277 & 20 & Reverse & GACAACCAACTACGAACCTC \\
\hline 13 & 6,264 & 6,281 & 18 & Reverse & CCAAGACAACCAACTACG \\
\hline 14 & 6,811 & 6,828 & 18 & Forward & TTACTATGGTGCATGCTG \\
\hline 15 & 7,748 & 7,767 & 20 & Forward & GTGAGAAAGGTGGTCGTTG \\
\hline 16 & 7,781 & 7,799 & 19 & Reverse & AACCAACACGCTTGTGATC \\
\hline 17 & 9,183 & 9,201 & 19 & Forward & ATGTTGTTGTGGCTGCTTG \\
\hline 18 & 9,267 & 9,289 & 23 & Reverse & TTAAAACCATCGATTAGAACCAC \\
\hline 19 & 10,321 & 10,339 & 19 & Reverse & GCAATCCTITCGTACTAAC \\
\hline 20 & 12,076 & 12,095 & 20 & Forward & TCGAGAGAGTATCTITGTAG \\
\hline 21 & 12,633 & 12,652 & 20 & Reverse & GCCAACCAAACCTACACATC \\
\hline 22 & 13,961 & 13,978 & 18 & Forward & GATGGTGTTGTGATGTGG \\
\hline
\end{tabular}

mitochondrial genomes of F. cobboldi (GenBank: NC_030529), F. elongatus (GenBank: NC_02800) as query sequences.

\section{DNA extraction, PCR, and sequencing}

The extraction of DNA from Fischoederius sp. 1 (Thailand) specimens was done as previously described [14]. The DNA was used in standard PCR for amplification of specific mitochondrial DNA fragments to either quality control transcriptome data or to add missing sequence data in the region between the ND2 and ND1 genes. The used primers and their details are listed in Table 1. PCR products were inserted into the pGEM $^{\circledR}$-T Easy vector (Promega, Wisconsin, USA) by standard ligation and had their sequences determined by Sanger dideoxy sequencing (SolGent, Daejeon, Korea and Macrogen, Daejeon, Korea).

\section{Analysis of mitochondrial sequence data}

Genes and functional RNAs in the mitochondrial genome of Fischoederius sp. 1 (Thailand) were identified by sequence comparison with the mitochondrial genomes of $F$. cobboldi (GenBank: NC_030529) and F. elongatus (GenBank: NC_02800). Furthermore, MITOS [15] was used for verification of mitochondrial genome annotation. All identified gene and functional RNA sequences were carefully inspected and their 5 and 3 ' ends were manually confirmed and corrected if necessary.
Table 2. Nucleotide sequence differences (\%) of mitochondrial genes in the genus Fischoederius

\begin{tabular}{lccc}
\hline & \multicolumn{3}{c}{ Compared species } \\
\cline { 2 - 4 } Gene & F1T/Fe & F1T/Fc & Fe/Fc \\
\hline COX3 & 9.9 & 9.9 & 10.5 \\
CYTB & 7.2 & 8.0 & 8.8 \\
ND4L & 9.1 & 8.0 & 8.7 \\
ND4 & 9.3 & 10.9 & 10.0 \\
ATP6 & 8.1 & 9.7 & 7.4 \\
ND2 & 10.6 & 10.4 & 10.3 \\
ND1 & 8.6 & 9.0 & 9.0 \\
ND3 & 12.3 & 11.2 & 11.5 \\
COX1 & 7.1 & 6.9 & 7.5 \\
COX2 & 6.5 & 6.2 & 6.0 \\
ND6 & 10.4 & 11.9 & 13.2 \\
ND5 & 10.7 & 10.8 & 11.1 \\
\hline
\end{tabular}

Fe: F. elongatus (GenBank: NC_028001), Fc: F. cobboldi (GenBank: NC_ 030529), F1T: Fischoederius sp. 1 (Thailand).

Pairwise nucleotide sequence alignments of all mitochondrial genes (COX3, CYTB, ND4L, ND4, ATP6, ND2, ND1, ND3, COX1, COX2, ND6, and ND5) of Fischoederius sp. 1 (Thailand), F. cobboldi (GenBank: NC_030529), F. elongatus (GenBank: NC_02800) genes were done in EMBOSS needle [16] to obtain sequence identity values (Table 2). The gapopen penalty was set to 30 to suppress invalid gaps.

The deduced amino acid sequences of all mitochondrial genes of Fischoederius sp. 1 (Thailand), F. cobboldi (GenBank: 
NC_030529), F. elongatus (GenBank: NC_02800), Gastrothylax crumenifer (GenBank: NC_027833), Calicophoron microbothrioides (GenBank: NC_027271), Explanatum explanatum (GenBank: NC_027958), Fasciola hepatica (GenBank: NC_002546), Homalogaster paloniae (GenBank: NC_030530), Ogmocotyle sikae (GenBank: NC_027112), Ogmocotyle sp JM 2015 (GenBank: KR006935), Orthocoelium streptocoelium (GenBank: NC_ 028071), Paramphistomum cervi (GenBank: NC_023095) were concatenated for each species and aligned in Clustal Omega [17] (Supplementary Fig. S1). Regions containing gaps were then removed in trimal [18]. Phylogenetic analysis of the alignment was performed in MrBayes 3.2.5 [19] using a Bayesian approach. The following parameters were used in the analysis: outgroup Fasciola hepatica, prset aamodelpr = mixed; $\mathrm{mcmc}$ nchains $=4$ ngen $=100,000$.

Partial COX1 sequences from India (GenBank: JX518952JX518954, JX518950, JX518951, JQ806364, and JQ806365) and Thailand (GenBank: MN437486-MN437488) were aligned in Clustal Omega with the corresponding region (base pairs 7031,065) of the COX1 gene from Fischoederius sp. 1 (Thailand), F. cobboldi (China, GenBank: NC_030529), F. elongatus (China, GenBank: NC_02800) (Supplementary Fig. S2).

\section{RESULTS}

\section{Morphology of Fischoederius sp. 1}

Fischoederius specimens were collected from a cow (Bos taurus indicus/Bos taurus hybrid) with a single infection spot in its rumen which suggested a single infection event. Moreover, molecular analysis of the mitochondrial COX1 gene from several worms showed the same sequence. The flukes in the rumen revealed a turgid, bottle-like appearance and reddishbrown color (Fig. 1A). The flukes were washed and kept in PBS and relaxed to a more elongated form (Fig. 1B). Microscopic examination revealed that all of the flukes were immature, i.e., the reproductive system was underdeveloped; thus eggs were absent from the flukes.

A small number of mature parasites with identical COX1 sequence was found in another cow that suffered from multiple infections. The image of an unstained specimen that was subsequently used for DNA extraction and COX1 sequencing is shown in Fig. 1C. Natural pigmentation limited the resolution of its morphology. Other Fischoederius specimens collected from this animal had significant different COX1 sequences and will be reported elsewhere. Carmine-stained mature and immature specimens were prepared to reveal the details of their morphology (Fig. 1D). Parasite morphology was found to be in general as described for $F$. elongatus [4,5]. In the mature parasite the lateral vitellaria fields extended from the distal end of the uterus at the genital pore down to the anterior testis. The ventral pouch opened in the area of the pharynx and extended to the posterior end of the anterior testis. The ovary was located between the lobed testes and the egg-filled sinusoid uterus progressed midline between the ceca and ended at the genital pore in the region of the cecal bifurcation. The distal end of the pair of slightly sinusoid ceca was within the anterior half of the body (Fig. 1D). The immature parasite had the same overall morphology but lacked visible vitellaria and showed only underdeveloped reproductive organs (Fig. 1D). Cross sections of an immature specimen (Fig. 2) showed further details similar to historical descriptions of $F$. elongatus (F. siamensis/F. fischoederi) [7]. Triangular form of the ventral pouch, location of the genital pore at the cecal bifurcation, maximum body diameter in the first third of the body, testes located at the caudal end of the ventral pouch, one anterodorsal to the other with the former located above the ventral pouch and the latter behind it.

\section{Mitochondrial genome of Fischoederius sp. 1}

The total RNA of 5 worms with confirmed identical COX1 sequence was pooled and used in a transcriptome project (BioProject PRJNA723375). Assembled transcript sequences identified by BLASTN as mitochondrial confirmed that the data originated from a single species but also showed that the mitochondrial data between the ND2 and ND1 genes was incomplete. For this reason PCR with genomic DNA was used to amplify this part of the mitochondrial genome and the ND2, ND1 genes were included to validate the transcriptome data. PCR amplification proceeded without problems but subsequent sequencing reactions failed 3' to ND2_tRNA-Val and 5' to tRNA-Asp_ND1. Based on PCR product sizes a region of approximate $750 \mathrm{bp}$ that should include the still missing tRNA-Ala sequence could not be resolved. Forward and reverse primers designed on a published Fischoederius tRNA-Ala sequence (GenBank: NC_028001) were then used to resolve sequences from inside this region together with primers binding outside. Tedious manual interpretation of the sequencing results allowed to resolve the full sequence. The difficulties were caused by 2 large inverted repeat units that obviously formed structures interfering with DNA synthesis during sequencing. 

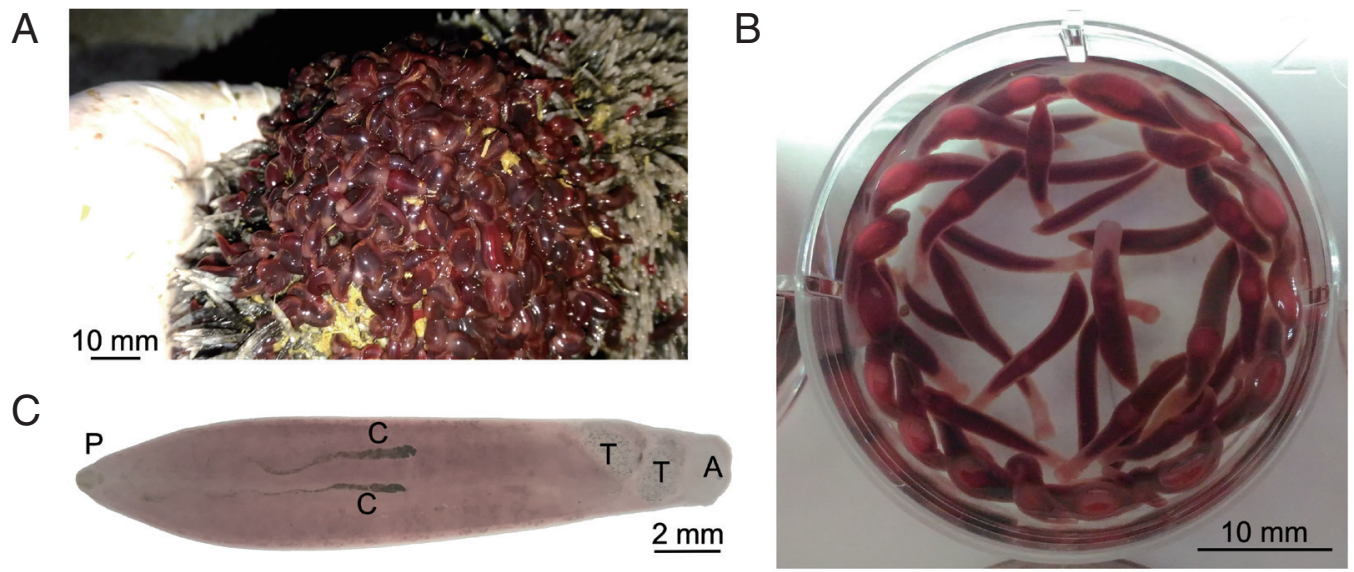

$\mathrm{D}$

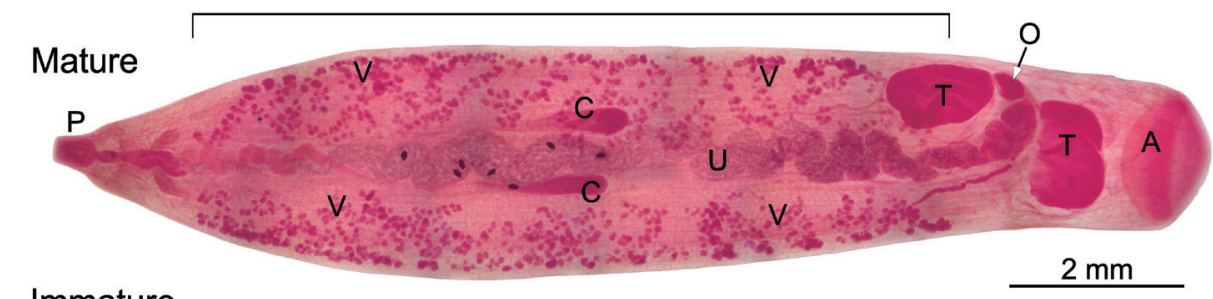

Immature

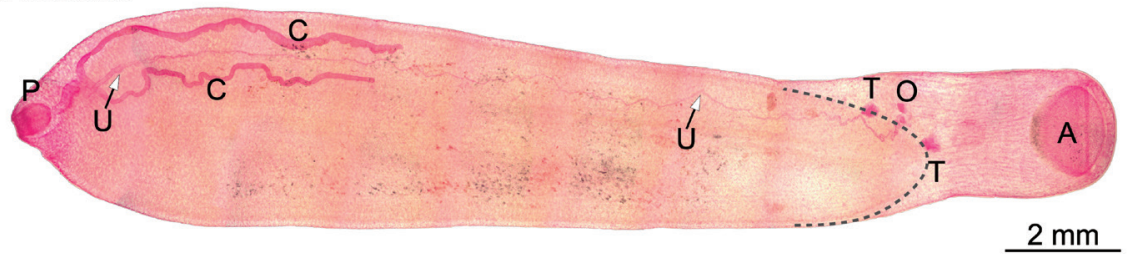

Fig. 1. Morphology of Fischoederius sp. 1, Thailand. (A) Cattle rumen with an infected spot covered with a large number of flukes showing turgid bottle-like appearance. (B) Immature flukes in PBS overnight at room temperature. (C) An unstained mature fluke. The COX1 sequence was determined from this specimen after taking photo. (D) Micrographs of carmine-stained mature and immature specimens. A stippled line outlines the distal end of the ventral pouch in the immature specimen. Acetabulum (A), intestinal ceca (C), ovary (O), phar$y n x(P)$, testes $(T)$, uterus $(U)$, vitellaria $M$ are indicated. The region of bilateral vitellaria fields is indicated by a horizontal line on top of the mature specimen.
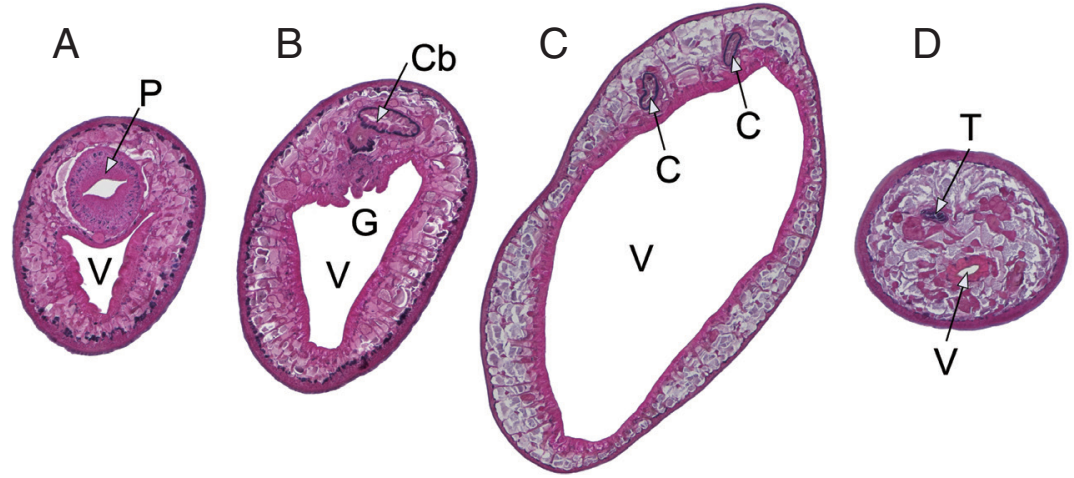

E
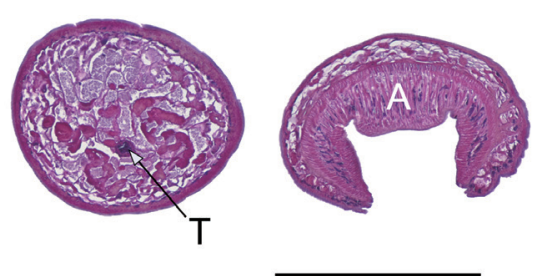

$1 \mathrm{~mm}$

Fig. 2. Cross sections, anterior to posterior, prepared from a single immature Fischoederius sp. 1 specimen, dorsal side up. Hematoxylin-eosin stained. $(A)$ pharynx $(P)$ and anterior end of triangular ventral pouch $(\mathrm{V})$. (B) cecal bifurcation (Cb) and genital pore (G). (C) the 2 ceca $(C)$ at maximum body diameter. (D) region containing the dorsoanterior testis $(T)$ and the posterior end of the ventral pouch. (E) ventrally positioned posterior testis. (F) muscular acetabulum (A). 


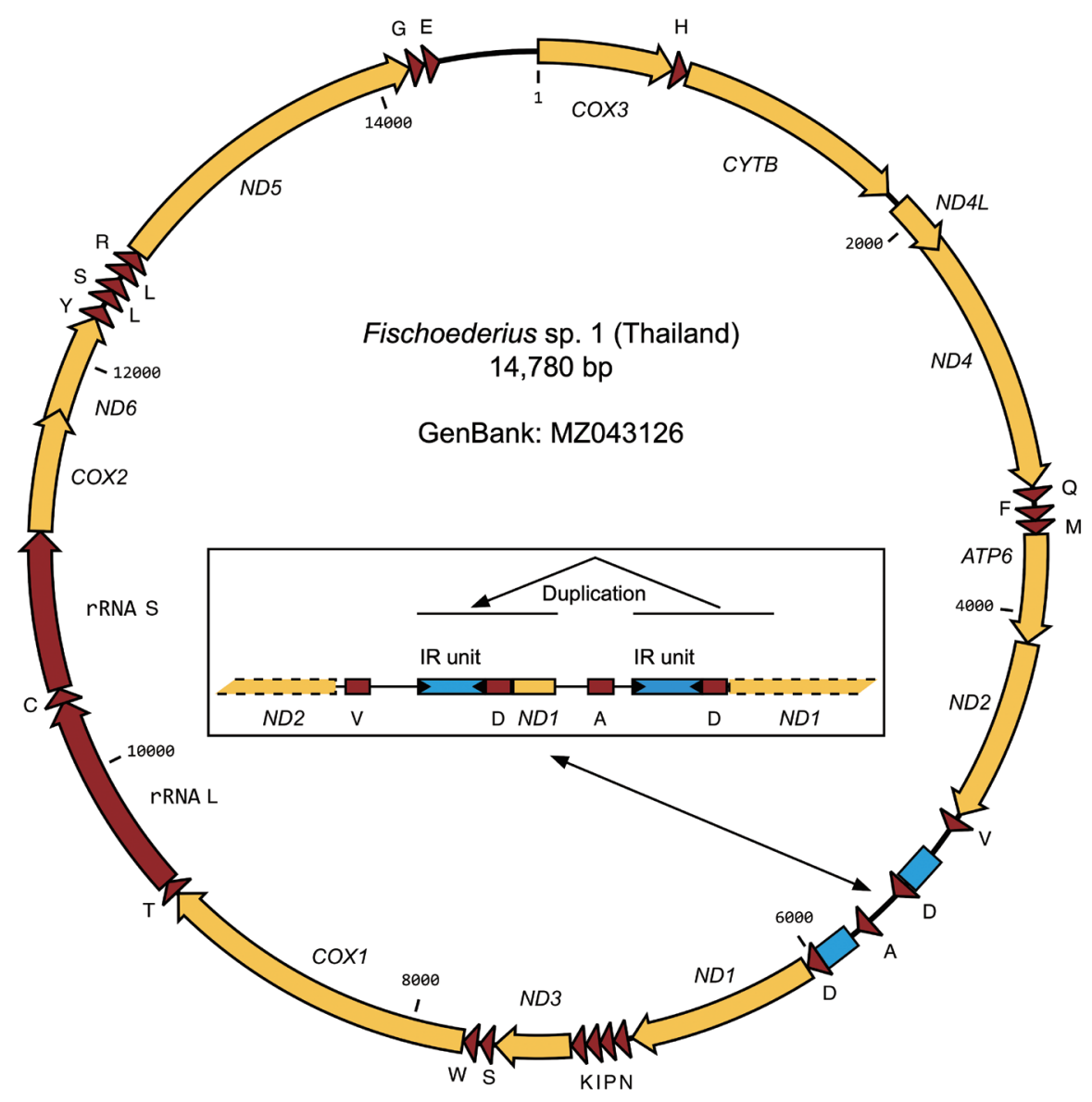

Fig. 3. Organization of the mitochondrial genome of Fischoederius sp. 1, Thailand. Protein coding regions are shown in yellow, functional RNA coding regions in red color. The tRNAs are indicated by the single letter code of their cognate amino acids. Two inverted repeat (IR) units are indicated in blue color. The inset shows details of the repetitive region which carries a duplication comprising repeat unit, tRNAD, and 5' region of ND1 gene.

The region including the repeats had a size of $746 \mathrm{bp}$ and included a second tRNA-Asp and a partial ND1 gene (117 bp of the gene's 5 '-end) followed by the expected tRNA-Ala (Fig. 3). The complete 14,780 bp mitochondrial genome of Fischoederius sp. 1 (Thailand) contained 12 protein coding genes in the order COX3, CYTB, ND4L, ND4, ATP6, ND2, ND1, ND3, COX1, COX2, ND6, ND5, 23 tRNAs in the order $\mathrm{H}, \mathrm{Q}, \mathrm{F}, \mathrm{M}, \mathrm{V}$, D, A, D, N, P, I, K, S, W, T, C, Y, L, S, L, R, G, E, and one each rRNA L and rRNA $S$ (Fig. 3). Sequence comparison of the 12 protein coding genes of Fischoederius sp. 1 (Thailand), F. elongatus (China), F. cobboldi (China) showed significant differences ranging from $6.0-13.2 \%$ (Table 2) that were far beyond intraspecies variation (nucleotide polymorphisms) and supported classification as 3 different species. A phylogenetic analysis of the 12 mitochondrial proteins between 12 trematodes confirmed the taxonomic position of Fischoederius sp. 1 (Thailand) in the Gastrothylacidae (Fig. 4). The alignment of the concatenated sequences used in this analysis had a length of 3,312 amino acids and covered $67.23 \%$ (9,936 bp) of the $14,780 \mathrm{bp}$ mitochondrial genome (Supplementary Fig. S1). Partial COX1 sequence data from India referring to F. elongatus (GenBank: JX518952- JX518954, JQ806365) was found to be identical with Fischoederius sp. 1 (Thailand) whereas partial F. elongatus COX1 sequence data recently reported from Thailand (GenBank: MN437486-MN437488) was different to the here reported data and the F. elongatus COX1 data from China and India (Supplementary Fig. S2).

\section{DISCUSSION}

In this research, we have demonstrated that a Fischoederius species collected from cattle in Thailand follows the classical 


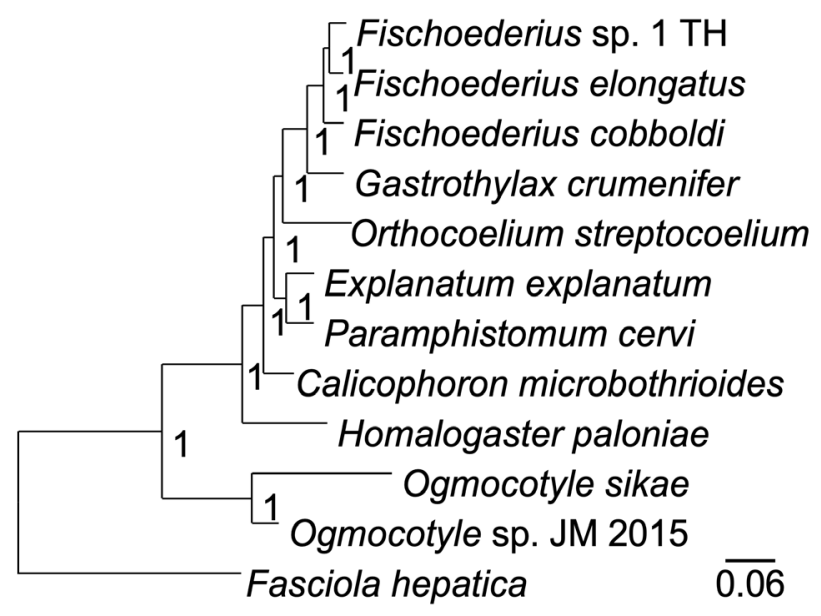

Fig. 4. A phylogenetic tree drawn on a multiple alignment of the deduced amino acid sequences of the 12 mitochondrial genes of the indicated trematode species. Fasciola hepatica was employed as an outgroup. The tree was calculated in MrBayes and the posterior probability values are shown at the branch nodes.

morphological description of $F$. elongatus [6,7]. Its complete mitochondrial genome sequence was determined and shown to be significantly different from those of $F$. elongatus [11] and $F$. cobboldi (GenBank: NC_030529) reported from China (Table 2; Figs. 3, 4). Moreover, partial F. elongatus COX1 sequences from Thailand [12] were different from our reported sequence and the mentioned sequences from China. Partial F. elongatus COX1 sequence data from India were consistent with our data and partial F. cobboldi COX1 sequence data from India [10] were in conflict with the F. cobboldi COX1 sequence from China (Supplementary Fig. S2). Thus, it must be assumed that there are several Fischoederius species with similar morphologies that need to be differentiated by molecular sequence data. Without molecular data from the original samples analyzed in 1883 [6] and 1910 [7] it will be difficult to assign either the correct species name or to decide that the molecular data originated from a new species. It is important to resolve these conflicting data to avoid ongoing confusion. In respect to the morphology of Fischoederius species, it is flexible and seems to be affected by crowding [20]. Thus, many parasites from different infected animals should be compared to conclude morphological flexibility.

The reported mitochondrial genome of Fischoederius sp. 1 follows in its overall organization those of the purported $F$. elongatus and F. cobboldi from China and the main interesting point should be the sequence duplication of tRNA-Asp and 5' end of ND1 (Fig. 4) that were likely caused by the inverted re- peats located next to them. These kinds of repeats are able to form stem loops that can lead to problems in replication and to illegitimate recombination [21]. The caused structural problems were very evident (1) in the transcriptome sequencing that lacked this region and (2) in our subsequent DNA Sanger sequencing attempts which needed to be repeated with a number of different primers from different locations until all data could be assembled.

\section{ACKNOWLEDGMENTS}

This work was funded by the Thailand Research Fund through a Royal Golden Jubilee Ph.D. scholarship to Pichanee Watthanasiri (PHD/0061/2556) and Thammasat University Research Unit in Parasitic Diseases.

Nucleotide sequences of Fischoederius sp. 1 (Thailand) in this paper are deposited in GenBank under accession number MZ043126 and BioProject PRJNA723375.

\section{CONFLICT OF INTEREST}

We declare that we have no conflict of interest related to this work.

\section{REFERENCES}

1. Sey O, Prasitirat P. Amphistomes (Trematoda, Amphistomida) of cattle and buffalo in Thailand. Miscnea zool hung 1994; 9: 11-17.

2. Pfukenyi DM, Mukaratirwa S. Amphistome infections in domestic and wild ruminants in East and Southern Africa: A review. Onderstepoort J Vet Res 2018; 85: 1-13. https://doi.org/10.4102/ ojvr.v85i1.1584

3. Chai JY, Shin EH, Lee SH, Rim HJ. Foodborne intestinal flukes in Southeast Asia. Korean J Parasitol 2009; 47 (suppl): 69-102. https://doi.org/10.3347/kjp.2009.47.S.S69

4. Sey O. Fischoederius Stiles et Goldberger, 1910. In Sey O ed, CRC Handbook of the Zoology of Amphistomes. Boca Raton, Florida. CRC Press. 1991; 301-307.

5. Jones A, Bray RA, Gibson DI. Keys to the Trematoda: Volume 2. Wallingford, UK. CABI, 2005.

6. Poirier J. Descriptions d'helminthes nouveaux du Palonia frontalis. Bull Soc philom Paris 1883; 7: 73-80.

7. Stiles CW, Goldberger J. A study of the anatomy of Watsonius (n. g.) watsoni of man and of nineteen allied species of mammalian trematode worms of the superfamily Paramphistomoidea. Bull Hyg Lab Publ Health Mar Hosp Service US 1910; 60: 1-259. https://doi.org/10.5962/bhl.title.104724 
8. Maplestone PA. A revision of the Amphistomata of mammals. Ann Trop Med Parasitol 1923; 17: 113-213. https://doi.org/10.10 80/00034983.1923.11684355

9. Ghatani S, Shylla JA, Tandon V, Chatterjee A, Roy B. Molecular characterization of pouched amphistome parasites (Trematoda: Gastrothylacidae) using ribosomal ITS2 sequence and secondary structures. J Helminthol 2012; 86: 117-124. https://doi.org/ 10.1017/S0022149X11000125

10. Ghatani S, Shylla JA, Roy B, Tandon V. Multilocus sequence evaluation for differentiating species of the trematode Family Gastrothylacidae, with a note on the utility of mitochondrial COI motifs in species identification. Gene 2014; 548: 277-284. https:// doi.org/10.1016/j.gene.2014.07.046

11. Yang X, Zhao Y, Wang L, Feng H, Tan L, Lei W, Zhao P, Hu M, Fang R. Analysis of the complete Fischoederius elongatus (Paramphistomidae, Trematoda) mitochondrial genome. Parasit Vectors 2015; 8: 279. https://doi.org/10.1186/s13071-015-0893-3

12. Nak-On S, Chontananarth T. Rumen fluke, Fischoederius elongatus (Trematoda: Gastrothylacidae): Preliminary investigation of suitable conditions for egg hatching. Vet Parasitol 2020; 282: 109135. https://doi.org/10.1016/j.vetpar.2020.109135

13. Chang Z, Li G, Liu J, Zhang Y, Ashby C, Liu D, Cramer CL, Huang $\mathrm{X}$. Bridger: a new framework for de novo transcriptome assembly using RNA-seq data. Genome Biol 2015; 16: 30. https://doi.org/ 10.1186/s13059-015-0596-2

14. Adisakwattana P, Viyanant V, Chaicumpa W, Vichasri-Grams S, Hofmann A, Korge G, Sobhon P, Grams R. Comparative molecular analysis of two asparaginyl endopeptidases and encoding genes from Fasciola gigantica. Mol Biochem Parasitol 2007; 156:
102-116. https://doi.org/10.1016/j.molbiopara.2007.07.006

15. Bernt M, Donath A, Jühling F, Externbrink F, Florentz C, Fritzsch G, Pütz J, Middendorf M, Stadler PF. MITOS: improved de novo metazoan mitochondrial genome annotation. Mol Phylogenet Evol 2013; 69: 313-319. https://doi.org/10.1016/j.ympev.2012. 08.023

16. Rice P, Longden I, Bleasby A. EMBOSS: the European Molecular Biology Open Software Suite. Trends Genet 2000; 16: 276-277. https://doi.org/10.1016/S0168-9525(00)02024-2

17. Sievers F, Wilm A, Dineen D, Gibson TJ, Karplus K, Li W, Lopez R, McWilliam H, Remmert M, Söding J, Thompson JD, Higgins DG. Fast, scalable generation of high-quality protein multiple sequence alignments using Clustal Omega. Mol Syst Biol 2011; 7: 539. https://doi.org/10.1038/msb.2011.75

18. Capella-Gutiérrez S, Silla-Martínez JM, Gabaldón T. trimAl: a tool for automated alignment trimming in large-scale phylogenetic analyses. Bioinformatics 2009; 25: 1972-1973. https://doi. org/10.1093/bioinformatics/btp348

19. Ronquist F, Huelsenbeck JP. MrBayes 3: Bayesian phylogenetic inference under mixed models. Bioinformatics 2003; 19: 15721574. https://doi.org/10.1093/bioinformatics/btg180

20. Tandon RS. Studies on "crowding effect" on Gastrothylax crumenifer and Fischoederius elongatus, the common amphistome parasites of ruminants, observed under natural conditions. Res Bull Meguro Parasit Mus 1973; 7: 12-14.

21. Lin CT, Lin WH, Lyu YL, Whang-Peng J. Inverted repeats as genetic elements for promoting DNA inverted duplication: implications in gene amplification. Nucleic Acids Res 2001; 29: 35293538. https://doi.org/10.1093/nar/29.17.3529 